\title{
Can Hampshires tolerate low lysine diets post weaning?
}

\author{
A E Taylor ${ }^{1}$, S Jagger ${ }^{2}$, P Toplis ${ }^{2}$, I Wellock ${ }^{2}, \mathrm{H}_{\mathrm{M}}$ Miller $^{1}$ \\ ${ }^{1}$ University of Leeds, Leeds, United Kingdom, ${ }^{2}$ AB Agri, Peterborough, United Kingdom \\ Email: bsaet@leeds.ac.uk
}

Introduction The UK pig industry has traditionally used a Large White sire over a Large White X Landrace dam (back cross). More recently there has been an increase in the use of three way crosses due to the improvements associated with hybrid vigour. Preliminary studies at the University of Leeds have shown that the Hampshire X (Large White X Landrace) pigs outperform Large White X (Large White X Landrace) pigs in terms of ADG due to a higher ADI. Due to the high cost of dietary protein, feeding strategies that can reduce protein in the diet are often used to reduce overall feed costs. As the Hampshire has a higher ADI compared to the Large White it may be that Hampshires can cope better with a low lysine diet. They may be able to compensate for the lower dietary lysine through a higher ADI. The aim of this study is to identify whether Hampshires can cope better when fed a low lysine diet post weaning compared to Large Whites.

Materials and methods A 2x2 factorial design compared growth of pigs on two lysine diets (low and high) and the growth performance of two cross bred genotypes (Hampshire X (Large White X Landrace) and Large White X (Large White X Landrace)). A total of 264 pigs (132 Hampshire X, 132 Large White X) were weaned at $28 \pm 4$ days, $8.2 \pm 0.16 \mathrm{~kg}$ and remained on trial for 20 days. Pigs were allocated to pens based on their genotype and balanced for weight and sex. Pigs were given ad-libitum access to either a low lysine diet $(0.80 \%)$ or a high lysine diet $(1.75 \%)$, above that recommended by the NRC (1998) to ensure performance was not limited. Diets were iso-energetic and formulated to the same amino acid:lysine ratios. Pigs were individually weighed at weaning (day 0 ) and then at 7, 14, and 20 days post weaning. Weekly pen feed intakes were recorded and feed conversion ratios (FCR) calculated throughout the trial. All pigs were checked for health daily. A General Linear Model (Minitab version 14.0) was used to analyse any differences in growth performance, health performance and feed intake between the pigs.

Results The results have shown that a reduction in dietary lysine reduced growth performance in both Hampshires and Large Whites. Pigs fed the high lysine diet were $2.1 \pm 0.12 \mathrm{~kg}$ heavier than pigs fed the low lysine diet at day 20 post weaning $(\mathrm{P}<0.001)$. Pigs fed the high lysine diet had a higher ADG and a more efficient FCR. ADI was not significantly different between pigs on the two diets (Table 1). From days 0-20 post weaning Hampshires grew faster in comparison to Large Whites due to a higher ADI. There was no difference in FCR between genotypes. The difference between the day 20 weights for Hampshires on the two diets was larger than the difference between the day 20 weights for Large Whites $(\mathrm{P}<0.001)$. Hampshires had a difference of $2.7 \pm 0.16 \mathrm{~kg}$ and Large Whites had a difference of $1.5 \pm 0.16 \mathrm{~kg}$ (Table 1$)$. There was no difference in health performance between any of the treatments.

Table 1 Growth performance $0-20$ days post weaning

\begin{tabular}{|c|c|c|c|c|c|c|c|c|}
\hline \multirow[b]{2}{*}{$\begin{array}{l}\text { Post Weaning } \\
\text { Performance }\end{array}$} & \multirow{2}{*}{$\begin{array}{l}\mathrm{H} \\
\text { High } \\
\text { Lysine }\end{array}$} & \multicolumn{3}{|c|}{ LW } & \multicolumn{4}{|c|}{ P-Value } \\
\hline & & $\begin{array}{l}\text { Low } \\
\text { Lysine }\end{array}$ & $\begin{array}{l}\text { High } \\
\text { Lysine }\end{array}$ & $\begin{array}{l}\text { Low } \\
\text { Lysine }\end{array}$ & SEM & Diet & Genotype & Interaction \\
\hline Wean weight $(\mathrm{kg})$ & 8.4 & 8.4 & 8.0 & 8.0 & 0.21 & 0.970 & $<0.005$ & 0.979 \\
\hline $20 \mathrm{~d}$ weight $(\mathrm{kg})$ & $15.8^{\mathrm{a}}$ & $13.1^{\mathrm{c}}$ & $14.1^{\mathrm{b}}$ & $12.6^{\mathrm{c}}$ & 0.16 & $<0.001$ & 0.000 & 0.001 \\
\hline $0-20$ d ADI (kg/d) & $0.411^{\mathrm{a}}$ & $0.383^{\mathrm{a}}$ & $0.321^{\mathrm{b}}$ & $0.339^{\mathrm{b}}$ & 0.0097 & 0.575 & $<0.001$ & 0.021 \\
\hline $0-20 \mathrm{~d}$ ADG $(\mathrm{kg} / \mathrm{d})$ & $0.381^{\mathrm{a}}$ & $0.248^{\mathrm{b}}$ & $0.296^{\mathrm{c}}$ & $0.222^{\mathrm{b}}$ & 0.0085 & $<0.001$ & $<0.001$ & 0.001 \\
\hline $0-20$ d FCR & $1.10^{\mathrm{a}}$ & $1.56^{\mathrm{b}}$ & $1.08^{\mathrm{a}}$ & $1.59^{\mathrm{b}}$ & 0.036 & $<0.001$ & 0.894 & 0.520 \\
\hline
\end{tabular}

Conclusions A reduction in dietary lysine reduced growth performance in both Hampshires and Large Whites. Hampshires were more sensitive to a low lysine diet post weaning. The different diets fed during the trial had an effect on the degree of growth reduction between the two genotypes. There was a bigger difference in weight between Hampshires fed the high and low diets compared to the weight difference between Large Whites on the two dietary treatments. ADI was not significantly different between genotypes on the two diets, suggesting that neither genotype could increase their feed intake to compensate for the lower lysine level. As in a preliminary trial carried out at the University of Leeds, Hampshires grew faster in comparison to Large Whites due to a higher ADI resulting in a higher ADG. Overall the results suggest Hampshires were less tolerant to a low lysine diet; they were faster growers and therefore may have a greater requirement for lysine.

Acknowledgements This research is supported by BBSRC and ABN.

\section{References}

NRC 1998. Nutrient Requirement of Swime. 10th Ed. (Washington, DC, National Academy Press). 